\title{
Long-term Dysphagia following Acoustic Neuroma Surgery: Prevalence, Severity, and Predictive Factors
}

\author{
Raiene Telassin Abbas-Kayano, ${ }^{1, \odot}$ Davi Jorge Fontoura Solla ${ }^{1} \quad$ Nicollas Nunes Rabelo ${ }^{1, \odot}$ \\ Marcos de Queiroz Teles Gomes ${ }^{1}$ Hector Tomas Navarro Cabrera ${ }^{1}$ Manoel J. Teixeira ${ }^{1, \odot}$ \\ Eberval Gadelha Figueiredo ${ }^{1}$
}

${ }^{1}$ Department of Neurosurgery, University of São Paulo, Brazil

Address for correspondence Eberval Gadelha Figueiredo, MD, PhD, Department of Neurosurgery, University of São Paulo, Brazil-Rua Eneas Aguiar, 255, São Paulo 05403-010, Brazil

(e-mail: ebgadelha@yahoo.com).

Indian J Neurosurg 2021;10:108-113.

\begin{abstract}
Keywords

Background Acoustic neuroma (AN) may compress the cerebellum and brainstem and may cause dysfunction of bulbar cranial nerves.

Objective To describe swallowing function outcomes in the late postoperative period after AN surgery.

Methods This cohort study included patients operated on between 1999-2014, with a mean follow up of $6.4 \pm 4.5$ years. The swallowing function was assessed through the functional oral intake scale (FOIS). The primary outcome was defined by scores 5 to 1 , which implied oral feeding restriction or adaptation. Risks factors were identified through multivariate logistic regression.

Results 101 patients were evaluated. As many as 46 (45.5\%) presented dysphagia on the late postoperative period. Women comprised $77.2 \%$, and the mean age was $47.1 \pm 16.0$ years (range 19-80). Dysphagic patients presented more type II neurofibromatosis (NF II) ( $32.6 \%$ vs. $10.9 \%, p=0.007$ ), larger tumors ( $3.8 \pm 1.1$ vs. $3.1 \pm 1.0 \mathrm{~cm}, p<0.001$ ), partial resection $(50.0 \%$ vs. $85.5 \%, p<0.001)$ and needed more surgeries $(\geq 2,39.1 \%$ vs. $18.2 \%$, $p=0.019$ ). Important peripheral facial palsy (PFP) (House-Brackmann [HB] grade $\geq 3$ ) was present before the surgery on $47.5 \%$ and worsened on $55.4 \%$. Postoperative PFP $(p<0.001)$, but not preoperative PFP, was predictive of postoperative dysphagia. On multivariate analysis, the following factors were risk factors for dysphagia: NF II (OR

- neurologic disorders

- dysphagia $5.54, p=0.034$ ), tumor size (each $1 \mathrm{~cm}, \mathrm{OR} 2.13, p=0.009$ ), partial resection (OR 5.23, $p=0.022$ ) and postoperative HB grade $\geq 3$ (OR 12.99, $p=0.002$ ).

- speech-language disorders and Conclusions Dysphagia after AN surgery is highly correlated to postoperative facial motor function. NF II, tumor size, and extent of resection were also predictive of this swallowing morbidity in the late postoperative period.
\end{abstract}

\section{Introduction}

Swallowing function is controlled at the early oral and pharyngeal stages by the cranial nerves trigeminal $(\mathrm{V})$, facial and intermedius (VII), glossopharyngeal (IX), and vagus (X), which provide afferent sensorial information and gustation. Cerebellopontine angle tumors, mainly acoustic neuroma

published online April 19, 2021
DOI https://doi.org/

$10.1055 / \mathrm{s}-0040-1719202$ ISSN 2277-954X.
(AN), may compress the cerebellum and brainstem and displace bulbar cranial nerves that are responsible for swallowing and speech functions. ${ }^{1,2}$

One survey of 1671 patients from the Acoustic Neuroma Association database revealed that $31 \%$ had swallowing problems during the postoperative period compared with $6.5 \%$ before the surgery. ${ }^{3}$ The prevalence of dysphagia after AN

(c) 2021. Neurological Surgeons' Society of India.

This is an open access article published by Thieme under the terms of the Creative Commons Attribution-NonDerivative-NonCommercial-License, permitting copying and reproduction so long as the original work is given appropriate credit. Contents may not be used for commercial purposes, or adapted, remixed, transformed or built upon. (https://creativecommons.org/licenses/by-nc-nd/4.0/).

Thieme Medical and Scientific Publishers Pvt. Ltd. A-12, 2nd Floor,

Sector 2, Noida-201301 UP, India 
surgery suggests that it may significantly impact patients' quality of life. ${ }^{4}$ Dysphagia management requires different strategies, such as speech therapy and diet modifications, to reduce its functional impact. Peripheral facial paralysis (PFP) is well-studied as a common neurologic impairment after AN surgery. However, few studies have adequately investigated the occurrence of long-term dysphagia. ${ }^{5,6}$ Therefore, this issue has been systematically neglected.

The present study aims to describe the swallowing function outcomes and identify its prognostic factors in the late postoperative period of patients submitted to AN surgery.

\section{Methods}

\section{Study Design and Population}

A cohort study was performed at the outpatient clinic. Adults patients ( $>18$ years old) operated between 1999 and 2014 were consecutively included, if they met the following criteria: absence of previous disabilities due to other neurological morbidities and clinical follow-up longer than 2 years.

\section{Dysphagia Assessment}

Dysphagia assessment was performed in two steps. The first was a structural evaluation, which consisted of analyses of the oral motor and sensory systems. The second step consisted of functional assessment of oral food intake assessed through the American Speech-Language-Hearing Association (ASHA) clinical bedside swallowing assessment protocol, ${ }^{7}$ and speech-language disorder protocol for introduction and transition of oral feeding. ${ }^{8}$ Functional oral intake was assessed, as described in - Table 1. Food consistency was evaluated according to the protocol described in - Table 2.

Additionally, patients were evaluated both clinically ( - Table 3) and using the functional oral intake scale (FOIS) (-Table 4). ${ }^{9}$ Scores 6 and 7 were considered as favorable, without interference on the daily food ingestion, whereas scores from 5 to 1 were deemed unfavorable.

\section{Data Collection and Variables}

Retrospective data collection was performed for the following variables: age, gender, type II neurofibromatosis (NF II) diagnosis, tumor size (measured from the auditory internal canal), PFP presence and House-Brackman $(\mathrm{HB})^{10}$ grade (preoperative and postoperative), surgical approach, extent of resection, and number of surgeries. Dysphagia was the primary outcome, as defined by the FOIS, which was prospectively evaluated. Data about preoperative dysphagia were not available for all patients.

\section{Data Analysis}

Categorical variables are presented as relative and absolute frequencies. Normally distributed continuous data are presented as mean and standard deviations and, otherwise, by median and quartiles. Categorical variables were compared between the groups through the Chi-square test. Continuous variables were evaluated through the student $t$-test or the Mann-Whitney U test, as appropriate.

Potential predictors of the primary outcome of dysphagia identified at the univariate analysis with a $p$ value
Table 1 Intake textures-speech and language pathology protocol for introduction and transition from oral feeding

\begin{tabular}{|c|c|}
\hline Level 01 & $\begin{array}{l}\text { Homogenous pasty (no } \\
\text { residue/pieces), very cohesive, not } \\
\text { requiring chewing skills. } \\
\text { (e.g., yogurt test) }\end{array}$ \\
\hline Level 02 & $\begin{array}{l}\text { Heterogeneous pasty (pasty with } \\
\text { pieces), cohesive, mixed, requiring } \\
\text { minimum chewing. This level excludes } \\
\text { bread, biscuits and other solid food } \\
\text { not mixed with creams or purees. (e.g., } \\
\text { yogurt with pieces) }\end{array}$ \\
\hline Level 03 & $\begin{array}{l}\text { Soft semisolid foods that require } \\
\text { greater chewing ability, excluding loose } \\
\text { grains, hard bread, green leaves and } \\
\text { other foods that are difficult to chew } \\
\text { or that tend to disperse into the oral } \\
\text { cavity. (e.g., soft bread). }\end{array}$ \\
\hline Level 04 & $\begin{array}{l}\text { Regular diet that includes all foods, } \\
\text { including any solid texture. (e.g., toast) }\end{array}$ \\
\hline Thin liquid: & $\begin{array}{l}\text { Liquid with water consistency in its } \\
\text { natural state. }\end{array}$ \\
\hline $\begin{array}{l}\text { Thin pasty } \\
\text { liquid: }\end{array}$ & $\begin{array}{l}\text { Liquid in the nectar consistency } \\
\text { (01 thicker measure). }\end{array}$ \\
\hline $\begin{array}{l}\text { Thick pasty } \\
\text { liquid: }\end{array}$ & $\begin{array}{l}\text { Liquid in honey consistency ( } 02 \text { thicker } \\
\text { measures). }\end{array}$ \\
\hline
\end{tabular}

Table 2 Intake modes-speech and language pathology protocol for introduction and transition from oral feeding

\begin{tabular}{|l|l|}
\hline Half tablespoon: & Equivalent to $3 \mathrm{~mL}$. \\
\hline Tablespoon: & Equivalent to $5 \mathrm{~mL}$. \\
\hline Full tablespoon: & Equivalent to $10 \mathrm{~mL}$ \\
\hline Controlled sip: & $\begin{array}{l}\text { Control of volume and rhythm by offering } \\
\text { liquid to the patient. }\end{array}$ \\
\hline Straw: & Supply of liquids with a straw \\
\hline Free sip: & $\begin{array}{l}\text { Supply of liquid is not controlled by the } \\
\text { speech therapist and the patient himself } \\
\text { conducts the volume and rhythm of the } \\
\text { intake of the liquid food. }\end{array}$ \\
\hline Dried pieces: & $\begin{array}{l}\text { Specific the supply of foods that do not } \\
\text { use utensils for holding, such as bread and } \\
\text { biscuits, which are offered without modifi- } \\
\text { cation in their current consistency. }\end{array}$ \\
\hline Moisty Pieces: & $\begin{array}{l}\text { Specifies the supply of foods that do not } \\
\text { use a holding utensil such as bread and } \\
\text { cookies, which are offered with a change } \\
\text { in their initial consistency, such as bread } \\
\text { dampened in milk. }\end{array}$ \\
\hline
\end{tabular}

under 0.10 were included in a multivariate logistic regression model, as well as age, independently of its significance. The model assumptions were assessed and were not violated.

All tests were bicaudal and final $p$-values under 0.05 were considered statistically significant. All analyses were conducted with the software Statistical Package for Social Sciences (IBM SPSS Statistics for Windows; IBM Corp., version 24.0, Armonk, NY, USA). 
Table 3 Clinical factors-speech and language pathology protocol for introduction and transition from oral feeding

\begin{tabular}{|l|}
\hline Level of alert, collaboration, and/or attention \\
\hline Impossibility to follow commands or simple orders \\
\hline Alteration of postural control \\
\hline $\begin{array}{l}\text { Impaired food retention. In this item, it was scored if the patient } \\
\text { had the inability to drink liquid from a glass, capture food from a } \\
\text { fork or spoon, and remove a piece of food through a bite; inabil- } \\
\text { ity to maintain food or liquid in the oral cavity, without any extra } \\
\text { oral escape between the labial commissures. }\end{array}$ \\
\hline $\begin{array}{l}\text { Impaired oral preparatory phase. In this item, the patient's inabil- } \\
\text { ity to form, contain and/or prepare the bolus for propulsion was } \\
\text { punctuated. }\end{array}$ \\
\hline $\begin{array}{l}\text { Delayed oral transit time. Determined by the triggering of the } \\
\text { swallowing reflex, it was considered slowed when oral transit } \\
\text { exceeded } 4 \text { seconds for liquid foods and } 20 \text { seconds for other } \\
\text { food consistencies. }\end{array}$ \\
\hline $\begin{array}{l}\text { Residues in the oral cavity. Residues of up to 25\% of the cake } \\
\text { offered in the oral cavity were considered as normal. }\end{array}$ \\
\hline Loss of food through the nose. \\
\hline Odynophagia. \\
\hline Wet voice. \\
\hline Premature spillage of food \\
\hline Decrease hyolaryngeal elevation and anteriorization \\
\hline $\begin{array}{l}\text { Multiple swallowing. Swallowing liquids, two for pastes and four } \\
\text { for solids, were considered adequate. }\end{array}$ \\
\hline Coughing before, during or after swallowing. \\
\hline Cough weak and ineffective. \\
\hline Spontaneous cloying. \\
\hline Choking. \\
\hline Alteration of cervical auscultation. \\
\hline Need for laryngeal cleaning under command. \\
\hline Oxygen saturation drop. \\
\hline Respiratory distress. \\
\hline Signs of general discomfort or clinical instability. \\
\hline
\end{tabular}

Table 4 FOIS

\begin{tabular}{|l|l|}
\hline Level & Description \\
\hline $\mathbf{0 1}$ & No oral intake \\
\hline $\mathbf{0 2}$ & Tube dependent with minimal/inconsistent oral intake \\
\hline $\mathbf{0 3}$ & Tube supplements with consistent oral intake \\
\hline $\mathbf{0 4}$ & Total oral intake of a single consistency \\
\hline $\mathbf{0 5}$ & $\begin{array}{l}\text { Total oral intake of multiple consistencies requiring } \\
\text { special preparation }\end{array}$ \\
\hline $\mathbf{0 6}$ & $\begin{array}{l}\text { Total oral intake with no special preparation, but must } \\
\text { avoid specific foods or liquid items }\end{array}$ \\
\hline $\mathbf{0 7}$ & Total oral intake with no restrictions \\
\hline
\end{tabular}

Abbreviation: FOIS, functional oral intake scale.

\section{Compliance with Ethical Standards}

The authors declare no conflict of interest. All participants participated voluntarily and signed an informed consent form. This research was submitted and approved by the local Ethics Committee.

\section{Results}

A total of 101 individuals were included. As many as 46 patients $(45.5 \%)$ presented with dysphagia in the late postoperative period. Men comprised $22.8 \%$ of the total sample, with a tendency to be more frequent on the dysphagic group (29.1\% vs. $15.2 \%, p=0.098)$. Mean age was $47.1 \pm$ 16.0 years (range 19-80), without differences between the groups. NF II was diagnosed in $20.8 \%$ of the patients. NF II was present in $32.6 \%$ of the dysphagic patients versus $10.9 \%$ of the nondysphagic ones $(p=0.007)$. The mean tumor size was $3.4 \pm 1.1 \mathrm{~cm}$ (range $0.7-6.2$ ). Large tumors were more prone to cause dysphagia ( $3.8 \pm 1.1 \mathrm{~cm}$ vs. $3.1 \pm 1.0 \mathrm{~cm} ; p<0.001)$. Retrosigmoid approach was chosen on $92.1 \%$, and total resection was achieved on $69.3 \%$. Half of the dysphagic patients underwent complete resection (versus $85.5 \%, p<0.001$ ). Multiple surgeries were statistically associated with dysphagia (39.1\% vs. $18.2 \% ; p=0.019$ ). Mean follow-up interval was $6.4 \pm 4.5$ years, similar for the two groups ( - Table 5 ).

Facial motor function before the surgery was compromised (HB grade $\geq 3$ ) on $47.5 \%$, and this percentage reached $75.2 \%$ on the follow-up. After the surgery, facial motor function worsened in 55.4\%. Postoperative PFP ( $p<0.001)$, but not preoperative PFP, was predictive of postoperative dysphagia (-Tables 6 and 7 and -Fig. 1A). As shown in -Fig. 1B the more severe the postoperative PFP, the more frequent the clinical signs reflect in oral dysfunction, oropharyngeal and pharyngeal phases of swallowing $(p<0.001)$.

In multivariate analysis, the following factors were predictive of dysphagia: NF II (OR 5.54, 95\% CI 1.13-27.07; $p=0.034$ ), tumor size (each $1 \mathrm{~cm}$, OR 2.13, 95\% CI 1.21-3.73; $p=0.009$ ), partial resection (OR 5.23, 95\% CI 1.27-21.46; $p=0.022$ ), and postoperative HB grade $\geq 3$ (OR 12.99, 95\%, CI 2.61-64.75; $p=0.002$ ).

\section{Discussion}

AN is an important and a well-recognized cause of neurological morbidity, with PFP being one of the most prevalent. Although a related disorder, the study of dysphagia in the late follow-up has been neglected and few data are available in the medical literature.

Almost half of our patients evolved with dysphagia after surgery and maintained it in the late postoperative period. Our sample had tumors (mean $3.4 \mathrm{~cm}$ ) slightly larger than to those reported in most studies $(<3 \mathrm{~cm}){ }^{1,2}$ This fact may lead to more significant compression of adjacent cranial nerves. Additionally, longer surgeries increase the risk of neuropathy in the postoperative period. ${ }^{111,12}$ These facts may have influenced our results.

In addition to the dysfunctions found in the oral phase of swallowing caused by PFP, $80 \%$ of the sample showed deficits related to the pharyngeal and oropharyngeal phases. In these phases, there is integration between the musculatures of the pharynges and phonoarticulatory organs. ${ }^{8}$ To the best of our 
Dysphagia following Acoustic Neuroma Surgery Abbas-Kayano et al. 111

Table 5 Patient characteristics according to FOIS

\begin{tabular}{|c|c|c|c|c|}
\hline \multirow[t]{2}{*}{ Variable } & \multirow[t]{2}{*}{ Total } & \multicolumn{2}{|c|}{ FOIS } & \multirow[t]{2}{*}{$p$-Value } \\
\hline & & Nondysphagic $(6-7)(n=55)$ & Dysphagic $(1-5)(n=46)$ & \\
\hline Age $(y)($ mean \pm SD) & $47.1 \pm 6.0$ & $48.0 \pm 15.5$ & $45.9 \pm 16.7$ & 0.514 \\
\hline Male gender & $23(22.8)$ & $16(29.1)$ & $7(15.2)$ & 0.098 \\
\hline Neurofibromatosis II & $21(20.8)$ & $6(10.9)$ & $15(32.6)$ & 0.007 \\
\hline $\begin{array}{l}\text { Tumor size }(\mathrm{cm}) \\
(\text { mean } \pm \text { SD) }\end{array}$ & $3.4 \pm 1.1$ & $3.1 \pm 1.0$ & $3.8 \pm 1.1$ & $<0.001$ \\
\hline Surgical approach & & & & 0.725 \\
\hline Retrosigmoid & $93(92.1)$ & $50(90.9)$ & $43(93.5)$ & \\
\hline Other $^{\mathrm{a}}$ & $8(7.9)$ & $5(9.1)$ & $3(6.5)$ & \\
\hline Total resection & $70(69.3)$ & $47(85.5)$ & $23(50.0)$ & $<0.001$ \\
\hline $\begin{array}{l}\text { Number of surgeries } \\
\text { (median and quartiles) }\end{array}$ & $1(1-2)$ & $1(1-1)$ & $1(1-3)$ & 0.017 \\
\hline $\begin{array}{l}\text { Two or more } \\
\text { surgeries }\end{array}$ & $28(27.7)$ & $10(18.2)$ & $18(39.1)$ & 0.019 \\
\hline $\begin{array}{l}\text { Follow-up (y) } \\
\text { (mean } \pm \text { SD) }\end{array}$ & $6.4 \pm 4.5$ & $6.2 \pm 4.7$ & $6.5 \pm 4.5$ & 0.806 \\
\hline
\end{tabular}

Abbreviation: FOIS, functional oral intake scale.

${ }^{a}$ Combined surgery or translabirintic approach.

Table 6 Association between preoperative and postoperative HB PFP grade and FOIS

\begin{tabular}{|c|c|c|c|c|}
\hline \multirow[t]{2}{*}{ Variable } & \multirow[t]{2}{*}{ Total } & \multicolumn{2}{|c|}{ FOIS } & \multirow[t]{2}{*}{ p-Value } \\
\hline & & Nondysphagic $(6-7)(n=55)$ & Dysphagic $(1-5)(n=46)$ & \\
\hline Preoperative HB grade & & & & 0.834 \\
\hline 1 & $33(32.7)$ & $16(29.1)$ & $17(37.0)$ & \\
\hline 2 & $20(19.8)$ & $14(25.5)$ & $6(13.0)$ & \\
\hline 3 & $18(17.8)$ & $5(9.1)$ & $13(28.3)$ & \\
\hline 4 & $10(9.9)$ & $10(18.2)$ & $0(0.0)$ & \\
\hline 5 & $4(4.0)$ & $2(3.6)$ & $2(4.3)$ & \\
\hline 6 & $16(15.8)$ & $8(14.5)$ & $8(17.4)$ & \\
\hline Postoperative HB grade & & & & $<0.001$ \\
\hline 1 & $12(11.9)$ & $12(21.8)$ & $0(0.0)$ & \\
\hline 2 & $13(12.9)$ & $10(18.2)$ & $3(6.5)$ & \\
\hline 3 & $17(16.8)$ & $13(23.6)$ & $4(8.7)$ & \\
\hline 4 & $21(20.8)$ & $11(20.0)$ & $10(21.7)$ & \\
\hline 5 & $13(12.9)$ & $3(5.5)$ & $10(21.7)$ & \\
\hline 6 & $25(24.8)$ & $6(10.9)$ & $19(41.3)$ & \\
\hline Dichotomized & & & & $<0.001$ \\
\hline Grades 1 or 2 & $25(24.8)$ & $22(40.0)$ & $3(6.5)$ & \\
\hline Grade 3 or worse & $76(75.2)$ & $33(60.0)$ & $43(93.5)$ & \\
\hline Variation & & & & $<0.001$ \\
\hline $\begin{array}{l}\text { Better or } \\
\text { maintained }\end{array}$ & $45(44.6)$ & $35(63.6)$ & $10(21.7)$ & \\
\hline Worse & $56(55.4)$ & $20(36.4)$ & $36(78.3)$ & \\
\hline
\end{tabular}

Abbreviations: FOIS, functional oral intake scale; HB, House-Brackman; PFP, peripheral facial palsy. Note: Data are presented as $n(\%)$. 
Table 7 Multivariate analysis for predictors of dysphagia according to the FOIS

\begin{tabular}{|l|l|l|l|l|l|l|}
\hline Variables & Coefficient & SE & Wald & OR & $95 \%$ CI & $p$-Value \\
\hline Age (each 10 years) & 0.01 & 0.02 & 0.31 & 1.01 & $0.98-1.04$ & 0.577 \\
\hline Male gender & -1.09 & 0.66 & 2.72 & 0.34 & $0.09-1.23$ & 0.099 \\
\hline Neurofibromatosis II & 1.71 & 0.81 & 4.47 & 5.54 & $1.13-27.07$ & 0.034 \\
\hline $\begin{array}{l}\text { Tumor size } \\
\text { (each 1 cm) }\end{array}$ & 0.75 & 0.29 & 6.92 & 2.13 & $1.21-3.73$ & 0.009 \\
\hline Partial resection & 1.65 & 0.72 & 5.27 & 5.23 & $1.27-21.46$ & 0.022 \\
\hline Two or more surgeries & 0.30 & 0.72 & 0.17 & 1.35 & $0.33-5.52$ & 0.680 \\
\hline $\begin{array}{l}\text { Postoperative HB } \\
\text { grade } \geq 3\end{array}$ & 2.56 & 0.82 & 9.80 & 12.99 & $2.61-64.75$ & 0.002 \\
\hline
\end{tabular}

Abbreviations: $\mathrm{Cl}$, confidence interval; FOIS, functional oral intake scale; HB, House-Brackmann; OR, odds ratio; SE, standard error.
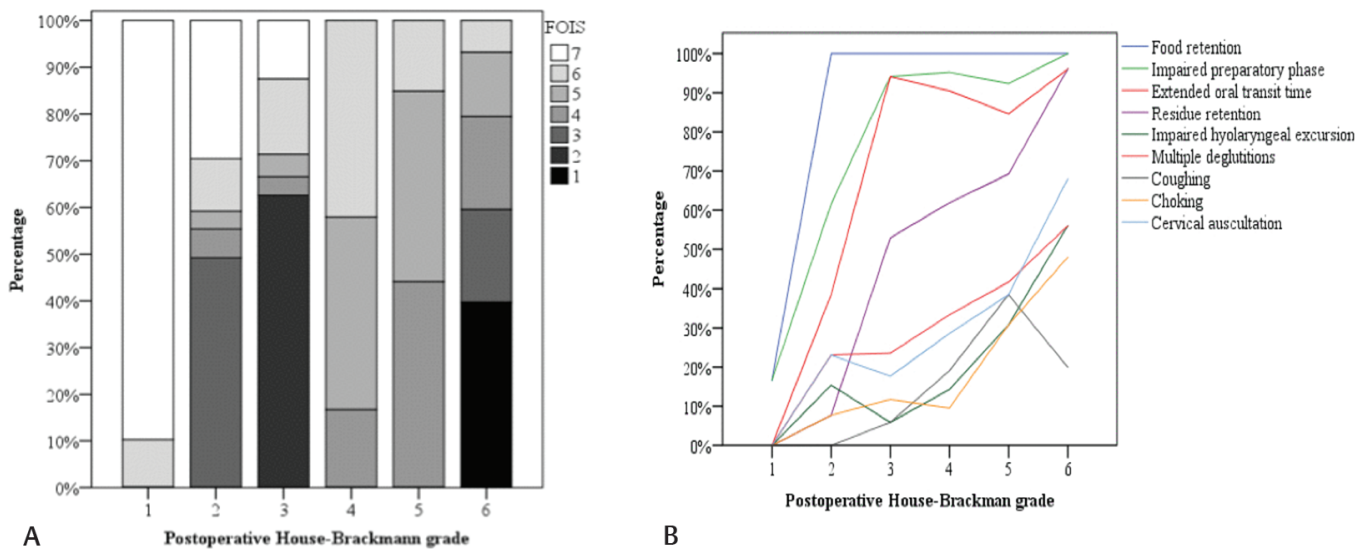

Fig. 1 (A) Association between dysphagia (FOIS) and postoperative peripheral facial palsy (PFP) (House-Brackmann [HB] grade). (B) Association of each clinical sign of laryngeal penetration/aspiration with PFP (HB grade).

knowledge, the association between PFP and oropharyngeal dysphagia in the late postoperative period (over 2 years) had not been described thus far, raising a new demand for rehabilitation. ${ }^{13}$ These findings may be due to the muscular dysfunction and the difficulty in maintaining their synergism, which is caused by facial nerve lesion. Pharyngeal phase impairments may also indicate that lower bulbar nerves have suffered some degree of injury. ${ }^{14}$

Regarding the clinical signs of swallowing abnormalities, we found that $80 \%$ of patients presented difficulties with thin liquid intake, demonstrating a direct association between the integration of phonoarticulatory organs and the induction of the pharyngeal phase of swallowing. Furthermore, patients reported a significant decrease in quality of life with adaptation for dry solid intake and the postural maneuvers for thin liquid intake. These findings are congruent with the literature, as deglutition disorders have a high impact in AN patients in the long-term follow-up. ${ }^{15}$ All dysphagic individuals reported that this is an impairment that profoundly interferes with daily life activities.

In a previous study, ${ }^{16}$ dysphagia was diagnosed immediately after surgery in $31 \%$ of the cases, $51 \%$ of whom had oral, $37 \%$ of oropharyngeal and $12 \%$ of pharyngeal involvement. PFP was observed in the immediate postoperative period in $91 \%$ of dysphagic patients. Our findings in the chronic phase are similar to that of the literature regarding the postoperative incidence and swallowing characteristics, which suggest that early postoperative deficits may persist and impact late outcomes. Additionally, we found a high-correlation between PFP and disabilities in oral, oropharyngeal and pharyngeal phases of swallowing. These findings emphasize that the follow-up by the speech-language pathologist, mainly in patients who evolve with cranial nerve dysfunction and evidence of PFP, may prevent or minimize persistent neurological morbidity. In this subset of patients, the assistance of speech-language pathologists may optimize oral intake, reduce health risks and costs, and increase the quality of life of these patients through specific rehabilitation programs.

\section{Limitations of the Study}

Although the dysphagia evaluation was prospective, this was mostly a retrospective cohort study and all inherent limitations may apply. The dysphagia diagnosis was made by clinical assessment, as is routine in clinical practice. Imaging examinations, including a functional endoscopic test of the swallowing function (functional endoscopic sinus surgery [FESS]), whose sensitivity is higher than that of clinical assessment alone, are reserved for dubious cases, so we cannot exclude that the incidence of dysphagia is higher. 
Some patients were operated without intraoperative physiological monitoring. It is not clear how the absence of monitoring could have impacted the dysphagia incidence.

\section{Conclusion}

Dysphagia is common after AN surgery and is highly correlated to postoperative facial motor function. NF II, tumor size, and extent of resection were also predictive of dysphagia in the late postoperative period.

\section{Highlights}

- AN may compress the cerebellum and brainstem and displace the bulbar cranial nerves.

- Dysphagia is common after AN surgery and is highly correlated to postoperative facial motor function.

- NF II, tumor size, and extent of resection were also predictive of morbidity in the late postoperative period.

- The assistance of speech-language pathologists may optimize oral intake, reduce health risks and costs, and increase the quality of life of these patients through specific rehabilitation programs.

\section{Funding}

None.

\section{Conflict of Interest}

None declared.

\section{References}

1 Samii M, Matthies C, Tatagiba M. Management of vestibular schwannomas (acoustic neuromas): auditory and facial nerve function after resection of 120 vestibular schwannomas in patients with neurofibromatosis 2. Neurosurgery 1997;40(4):696-705, discussion 705-706

2 Nikolopoulos TP, Fortnum H, O’Donoghue G, Baguley D. Acoustic neuroma growth: a systematic review of the evidence. Otol Neurotol 2010;31(3):478-485
3 Ryzenman JM, Pensak ML, Tew JM Jr. Patient perception of comorbid conditions after acoustic neuroma management: survey results from the acoustic neuroma association. Laryngoscope 2004;114(5):814-820

4 Harris C. Neurofibromatosis type 2-living with the complications: a case study. J Neurosci Nurs 2005;37(3):156-158

5 Bento RFBV, Paralisa facial periférica In: Tratado de Otorrinolaringologista Sao Paulo: Roca; 1994 888-911

6 Carvalho A, Preferência mastigatoria em pacientes com paralisia facial periférica de duração igual ou superior a seis meses: estudo clínico e eletromiográfico. São Paulo, Brazil: Faculdade de Medicina da Universidade de São Paulo; 2008

7 American Speech-Language-Hearing Association. (n.d.). Adult Dysphagia. (Practice Portal). Available at: www.asha.org/ Practice-Portal/Clinical-Topics/Adult-Dysphagia/. Accessed July 22, 2018

8 Padovani A, Protocolo fonoaudiológico de introdução e transição da alimentação via oral para usuários com risco de disfagia (PITA). São Paulo, Brazil: Faculdade de Medicina da Universidade de São Paulo; 2010

9 Crary MA, Mann GD, Groher ME. Initial psychometric assessment of a functional oral intake scale for dysphagia in stroke patients. Arch Phys Med Rehabil 2005;86(8):1516-1520

10 House JW, Brackmann DE. Facial nerve grading system. Otolaryngol Head Neck Surg 1985;93(2):146-147

11 Tees D, Lofchy N, Rutka J. Deafness, dysphagia and a middle ear mass in a patient with neurofibromatosis type 2. J Otolaryngol 1992;21(3):227-229

12 Eibling DE, Boyd EM. Rehabilitation of lower cranial nerve deficits. Otolaryngol Clin North Am 1997;30(5):865-875

13 Jennings KS, Siroky D, Jackson CG. Swallowing problems after excision of tumors of the skull base: diagnosis and management in 12 patients. Dysphagia 1992;7(1):40-44

14 Netterville JL, Civantos FJ. Rehabilitation of cranial nerve deficits after neurotologic skull base surgery. Laryngoscope 1993;103(11 Pt 2) (Suppl 60):45-54

15 Tucker HM. Rehabilitation of patients with postoperative deficits cranial nerves VIII through XII. Otolaryngol Head Neck Surg (1979) 1980;88(5):576-580

16 Starmer HM, Best SR, Agrawal Y, et al. Prevalence, characteristics, and management of swallowing disorders following cerebellopontine angle surgery. Otolaryngol Head Neck Surg 2012;146(3):419-425 